\title{
Malignant Testicular Sex Cord-Stromal Tumor
}

National Cancer Institute

\section{Source}

National Cancer Institute. Malignant Testicular Sex Cord-Stromal Tumor. NCI Thesaurus.

Code C39948.

A malignant sex cord-gonadal stromal tumor that arises from the testis. It is

characterized by cellular pleomorphism, anaplastic features, increased mitotic activity, and vascular invasion. 